\title{
A CASE OF CHILDHOOD RECALCITRANT GRANULOMA ANNULARE SUCCESSFULLY TREATED WITH TOPICAL TACROLIMUS
}

Lakshman Das ${ }^{1}$, Gautam Mazumder²

\section{HOW TO CITE THIS ARTICLE:}

Lakshman Das, Gautam Mazumder. "A Case of Childhood Recalcitrant Granuloma Annulare Successfully Treated with Topical Tacrolimus". Journal of Evolution of Medical and Dental Sciences 2014; Vol. 3, Issue 23, June 09; Page: 6474-6477, DOI: $10.14260 /$ jemds/2014/2766

ABSTRACT: A 5years old boy presented to us with skin colored to erythematous papules which coalesced to form annular plaques with a tendency to spread centrifugally with mild atrophy in the center for a duration of 9 months. The clinical and histopathological findings confirmed the case to be a generalized granuloma annulare of interstitial type. He was successfully treated with topical tacrolimus $(0.1 \%)$ which was earlier failed to respond satisfactorily with topical and systemic steroid. The case was followed up for duration of another 6 weeks and did not show any signs of relapse or tacrolimus associated adverse effects.

KEYWORDS: Tacrolimus, recalcitrant, granuloma annulare.

INTRODUCTION: Granuloma annulare (GA) is an inflammatory disorder of the dermis and/or subcutis characterized by degeneration of connective tissue and a surrounding infiltrate which is predominantly histiocytic. ${ }^{1}$ It can occur at any age but overall is commonest in children and young adults. The most common sites to be involved are the backs of the hands, fingers, dorsum of the feet, legs and forearm. ${ }^{2}$

The clinical variants of GA are localized, disseminated or generalized, nodular, perforating, and subcutaneous. GA often presents with papules, the centers of which may be slightly hyper pigmented and depressed relative to their borders. Generalized GA is characterized by numerous papules and annular plaques symmetrically distributed on the trunk and extremities. Lesions are usually asymptomatic, but rarely it may be pruritic or painful.

The cause of GA is unknown, but it has been reported to follow trauma, malignancy, viral infections (including human immunodeficiency virus, Epstein-Barr virus and herpes zoster), insect bites and tuberculosis skin tests. ${ }^{3}$ It is ultimately a self-limiting condition and only very rarely has been associated with tissue destruction and scarring. ${ }^{4}$

Different treatment modalities like cryotherapy, scarification, topical and systemic steroids, antimalarials, chlorambucil, ciclosporin, dapsone, etretinate, fumaric acid esters, isotretinoin, niacinamide, pentoxifylline, photo(chemo)therapy, potassium iodide, zileuton (a 5-lipoxygenase inhibitor), vitamin E have been tried with variable responses. ${ }^{1}$ Recent reports suggest topical tacrolimus may be helpful. ${ }^{5}$

History: A 5years old boy weighing 20kgs presented to us with skin colored to erythematous papules which coalesced to form annular plaques with a tendency to spread centrifugally with mild atrophy in the center. Initially, the lesions started over the dorsum of both hands and forearms in a symmetrical fashion and gradually spread to involve both legs and feet in a duration of 9 months (Figure: 2). It was insidious in onset and was not associated with any constitutional symptoms. No history of any seasonal variation, aggravating or reliving factors. No evidence of scaling. General examination did 
not reveal any abnormality. Complete blood count, urine analysis, liver function test, plasma glucose level, chest X-ray, mantaux test, C-reactive protein ASO titre and serology for HIV were all normal.

Histopathological examination of skin biopsy shows the entire reticular dermis was thickened with collagen bundles between which are splayed small collections of histiocytes that partially surround small foci of necrobiosis (Figure. 1). So, the clinical and histopathological findings confirmed the case to be a generalized granuloma annulare of interstitial type.

He was put on moderate potency topical steroid (mometasone $0.1 \%$ cream twice daily application) along with systemic corticosteroid (prednisolone $20 \mathrm{mg}$ daily i.e. $1 \mathrm{mg} / \mathrm{kg} /$ day). After 4 weeks of therapy the lesions started regressing in size and completely disappeared in 6 weeks and the steroids were tapered over next 4weeks. The patient developed topical steroid induced mild atrophy and hypopigmentation around the perilesional areas.

The lesions started relapsing rapidly after stopping the treatment. So, we considered alternate therapy solely with topical tacrolimus $0.1 \%$ twice daily application. After 4 weeks of treatment, the lesions started regressing with near complete clearance at the sites with remnant hyper pigmentation over next 4 weeks (Figure. 3). We continued the treatment for another 2 weeks.

The patient remains in a satisfactory clinical remission without any relapse of lesions up to a 6 weeks post therapy follow up. During the treatment with topical tacrolimus, the patient had not reported any side effects such as paraesthesia, burning sensation, itching or skin atrophy associated with tacrolimus as mentioned in literature.

DISCUSSION: The most characteristic histological lesion in granuloma annulare is the necrobiotic granuloma. But there are three histological patterns that may occur: necrobiotic palisading granuloma, an interstitial form, and granuloma of sarcoidal or in tubercular type. Necrobiotic granuloma is characterized by foci of necrobiosis surrounded by histiocytes and lymphocytes with histiocytes commonly forming a palisade pattern.

Analysis of T-cell repertoire and cytokine pattern has shown a T-cell response characterized by a combination of few skin specific clones together with many non- specific T- cells and abundant production of interleukin-2 (IL-2). The high local production of interleukin-2 could be responsible for the non-specific attraction of T-cells to the granuloma. ${ }^{6}$

Histologically, GA is characterized by lymphohistiocytic granulomas, with various degrees of collagen degeneration, micro droplet lipid accumulation and mucin deposition. Immunocyto chemical studies have shown a predominance of interleukin (IL)-6 and tumour necrosis factor (TNF- $\alpha$ ) in GA and other granulomatous conditions. ${ }^{7}$ Other studies analyzing intralesional cytokine expression in GA revealed abundant production of IL-28,9 which was thought to play an important role in the nonspecific attraction of $\mathrm{T}$ cells to the granulomatous site.

Tacrolimus is a macrolide lactone; calcineurin inhibitor, cause inhibition of IL-2 and T-cell derived cytokines like TNF- $\alpha$, and other interleukins. ${ }^{10}$ It also inhibits the transcription and release of other cytokines (e.g. IL-3, IL-4, IL-5, TNF- $\alpha$ and granulocyte/macrophage colony-stimulating factor), which can contribute to allergic inflammation. ${ }^{11}$ Unlike corticosteroids, which modify functions and growth of many cell types including fibroblasts and keratinocytes, tacrolimus acts specially on inflammatory cells. ${ }^{12}$

The exact mechanism of action of tacrolimus in GA is not known but the capacity of tacrolimus to inhibit the activation of different cytokines (IL-2 and TNF- $\alpha$ ) may account for its ability 
to reduce inflammation and to treat GA effectively. And also immunomodulatory effects with suppression of the granulomatous infiltrates, including reduction of chemotactic activity of fibroblasts and the inhibition of collagen synthesis. ${ }^{13}$

Tacrolimus in its topical formulation has been established as a safe and effective alternative to topical corticosteroids because of its mild side effects and its minimal systemic absorption. However, in our case, we are reporting this case, firstly because of its frequent relapses with steroid therapy which was successfully controlled with topical tacrolimus. Secondly, because of its rarity of reporting of successful treatment of childhood disseminated granuloma annulare with topical tacrolimus only.

\section{REFERENCES:}

1. John Harper, Arnold Oranje and Neil Prose: Granuloma annulare- Textbook of Pediatric Dermatology. Vol. I; Edn-2nd, Blackwell Publishing, 2006, 889-900.

2. Wells RS, Smith MA. The natural history of granuloma annulare. Br J Dermatol 1963; 75: 199 205.

3. Smith MD, Downie JB, DiCostanzo D. Granuloma annulare. Int J Dermatol 1997; 36: 326-33.

4. Dabski K, Winkelmenn RK. Generalised granuloma annulare: clinical \& laboratory findings in 100 patients. J Am Acad Dermatol 1989; 20: 39-47.

5. Jain, S. and Stephens, C. (2004), Successful treatment of disseminated granuloma annulare with topical tacrolimus. British Journal of Dermatology, 150: 1042-1043. doi: 10.1111/j.1365-2133. 2004.

6. Tony Burns, Stephen Breathnach, Neil Cox and Christopher Griffiths: Granuloma annulareRook`s Textbook of Dermatology. Vol-3; Edn-7th, Blackwell Publishing, 2004, 57.109-57.119.

7. Ahmed AA, Nordlind K, Schultzberg M, Liden S. Interleukin-1 alpha- and beta-, interleukin-6and tumour necrosis factor-alpha-like immunoreactivities in chronic granulomatous skin conditions. Acta Derm Venereol (Stockh) 1994; 74: 435-40.

8. Modlin RL, Horwitz DA, Jordan RR et al. Immunopathologic demonstration of T-lymphocyte subpopulations and interleukin 2 in granuloma annulare. Pediatr Dermatol 1984; 2: 26-32.

9. Mempel M, Musette P, Flageul B et al. T-cell receptor repertoire and cytokine pattern in granuloma annulare: defining a particular type of cutaneous granulomatous inflammation. J Invest Dermatol 2002; 118: 957-66.

10. Kang S, Lucky AW, Parser D et al. Tacrolimus ointment study group. Long term safety and efficacy of tacrolimus ointment in the treatment of atopic dermatitis in children. J Am Acad Dermatol 2001; 44: S58-64.

11. Tocci MJ, Matkovich DA, Collier KA et al. The immunosuppressant FK506 selectively inhibits expression of early T cell activation genes. J Immunol 1989; 143: 718-26.

12. Ehrchen J, Sunderkötter C, Luger T, Steinhoff M. Calcineurin inhibitors for the treatment of atopic dermatitis. Expert Opin Pharmacother 2008; 9: 3009-3023. Rallis E, Korfitis C, Gregoriou S, Rigopoulos D. Assigning new roles to topical tacrolimus. Expert Opin Invest Drugs 2007; 16: 1267-1276.

13. Carroll CL, Fleischer AB Jr. Tacrolimus ointment: the treatment of atopic dermatitis and other inflammatory cutaneous disease. Expert Opin Pharmacother 2004; 5: 2127-2137. 


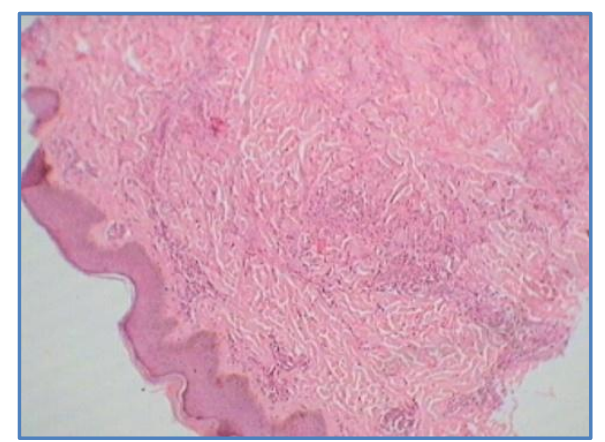

Fig. 1: Histopathology shows the entire reticular dermis has thickened collagen bundles between which are splayed small collections of histiocytes that partially surround small foci of necrobiosis.

\section{Before Treatment}

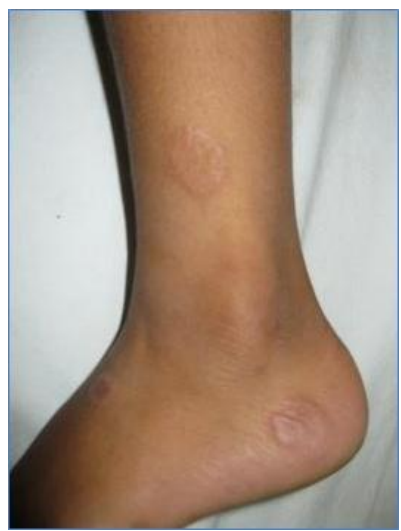

Fig. 2: Multiple erythematous annular Plaque with mild central atrophy on the lateral aspect of leg

\section{After Treatment}

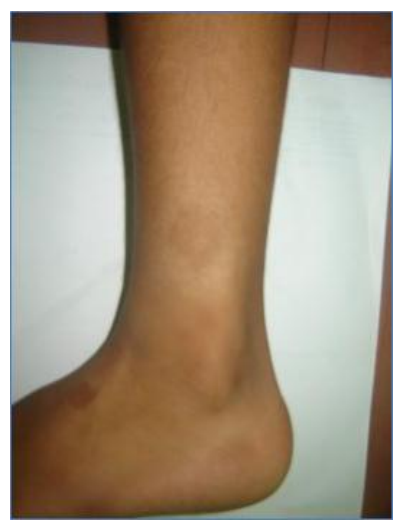

Fig. 3: Complete clearance of the lesions with remnant mild hyperpigmentation

\section{AUTHORS:}

1. Lakshman Das

2. Gautam Mazumder

\section{PARTICULARS OF CONTRIBUTORS:}

1. Assistant Professor, Department of Pharmacology, Tripura Medical College and Dr. B. R. Ambedker Memorial Teaching Hospital, Hapania, Agartala, Tripura.

2. Associate Professor, Department of Dermatology, Tripura Medical College and Dr. B. R. Ambedker Memorial Teaching Hospital, Hapania, Agartala, Tripura.

\section{NAME ADDRESS EMAIL ID OF THE}

\section{CORRESPONDING AUTHOR:}

Dr. Lakshman Das, Assistant Professor, Department of Pharmacology, Tripura Medical College and Dr. B. R. Ambedker Memorial Teaching Hospital,

Hapania, Agartala, Tripura.

E-mail: doctorldas@gmail.com

Date of Submission: 22/05/2014.

Date of Peer Review: 23/05/2014.

Date of Acceptance: 28/05/2014.

Date of Publishing: 07/06/2014. 